\title{
DISCURSO DEL RECTOR DE LA UNIVERSIDAD DE LA SERENA
}

\author{
Jaime Pozo Cisternas
}

Constituye un gran honor para el Rector de la Universidad de La Serena la invitación del profesor Luis Riveros Cornejo, Rector de la Universidad de Chile, para participar en el Seminario de Conmemoración del Bicentenario del Natalicio de Ignacio Domeyko, que organiza esta Casa de Estudios Superiores.

En consideración a que la influencia de tan connotado sabio polaco está enraizada en la historia de esta Universidad y de la que represento, me resulta que, además de un honor, es un deber que asumo con gran respeto y admiración por esta relevante personalidad de trascendencia nacional e internacional.

Invaluables fueron los servicios que Ignacio Domeyko prestó a Chile durante casi el medio siglo que permaneció y vivió en el país, entre otros, impulsando y desarrollando la naciente ciencia nacional, aportando valor a la industria minera del país, reformando la educación superior, estableciendo tradiciones pedagógicas en la enseñanza de las ciencias, contribuyendo al conocimiento de Chile en el extranjero, e incorporando en la vida nacional importantes aspectos de la cultura y de la civilización del mundo europeo.

En el transcurso del seminario tendremos ocasión de conocer variados aspectos de la vida de Ignacio Domeyko, los que nos serán presentados por expertos especialmente invitados. Particularmente y atendida también mi condición de Profesor de Química, haré mención, dentro de la polifacética dimensión humana de Ignacio Domeyko, a algunos hechos de su vida como hombre de ciencias, dando una mirada muy sucinta a su labor de docente y de investigador.

Casi a las dos décadas de estarse formando en Chile el Estado Republicano, el Gobierno de Chile, impulsando como política de Estado el desarrollo de las Ciencias Naturales, contrata a connotados científicos europeos, entre ellos al provenzal Claudio Gay, quién llegó a Chile el 8 de diciembre de 1828 y 10 años más tarde al sabio polaco Ignacio Domeyko. 
En efecto, el 3 de junio de 1838 Domeyko llegó a La Serena, contratado por el Gobierno Chileno como Profesor del Curso de Química y Mineralogía del Instituto Departamental de Coquimbo (actual Liceo de Hombres de La Serena).

En septiembre de 1838 luego de tres meses de aprendizaje del idioma, Domeyko decide iniciar sus clases en el Instituto de Coquimbo, pero reconociendo la total ausencia de formación en ciencias y el desconocimiento de la mineralogía como ciencia, toma la sabia decisión que dejó registrada en su diario "Dada la confianza ilimitada que se tenía en mí, la única norma y el único deber era guiarme por la honestidad e idear sólo aquello que pudiera redundar en beneficio de mis futuros alumnos y el hospitalario país. Decidí, pues, establecer un plan diferente al que por lo común se atienen los pedagogos en las escuelas y adaptarme a la inteligencia de los alumnos, a quienes aún no conocía, y también a sus reales ventajas y necesidades".

Se pregunta a continuación: “ipodía yo acaso comenzar por la mineralogía, tal como se la imaginaban aquí, cuando los muchachos no tenían el menor conocimiento de las ciencias básicas?, había que empezar por los principios elementales de la física experimental, agudizar en ellos la curiosidad de los oyentes y, al mismo tiempo, mostrar la utilidad de la ciencia".

Así, en aquel septiembre de 1838 y con sólo 15 alumnos, Domeyko inicia sus clases de ciencias con un curso de física experimental que se extendería por tres meses hasta el término del año escolar, dando inicio en Marzo siguiente al curso de Química y Mineralogía.

Como Profesor de Química y Mineralogía en el Instituto de Coquimbo y más tarde en el Instituto Nacional de Santiago, Domeyko estableció una innovadora escuela pedagógica para la época, basada en novedosas metodologías de enseñanza de las ciencias, las que han trascendido en el tiempo y que hoy deberían estar plenamente vigentes.

En sus técnicas de enseñanza fueron destacables las lecciones prácticas y los experimentos cuyos resultados estimulaban a su vez, la comunicación entre él y los estudiantes. Este método didáctico despertaba la curiosidad de los alumnos y les instaba a interesarse por el aprendizaje de las ciencias y sus aplicaciones.

Fuera de sus períodos de clases realizó exploraciones de reconocimiento del territorio nacional, logrando importantes observaciones y descubrimientos científicos que compartía con sus alumnos en clases, iniciándolos en el trabajo de investigación científica. Incluso a estas excursiones invitaba a sus estudiantes, para que así ellos reforzaran sus 
conocimientos teóricos con la práctica de terreno y desarrollaran las habilidades de observación y reflexión que favorecían también su formación intelectual y desarrollo personal.

Llevó también la ciencia al conocimiento de la comunidad, organizando con los alumnos exposiciones científicas a través de experimentos que se hacían públicos, como una suerte de dar cuenta de su trabajo. Esta labor de extensión contribuiría a una mejor comprensión del ciudadano común de las leyes básicas de la ciencia y su aplicación en la vida cotidiana. Es un aspecto en el que podemos reconocer su modernidad a través de las primeras prácticas de "accountability", al dar cuenta pública de los logros de su enseñanza a través de las presentaciones que hacían los estudiantes de sus aprendizajes a la comunidad.

Todo el material de enseñanza que utilizó en sus clases de ciencias, lo transportó desde Francia en treinta grandes cajones que llegaron al Puerto de Coquimbo; estos contenían equipos de laboratorio de química, física, mineralogía y muestras mineralógicas para ilustrar la teoría; tuvo que encargarse de variadas tareas, como la supervisión de la construcción cle los laboratorios de química y mineralogía, así como promocionar entre los jóvenes el interés por estudiar las disciplinas de la química y la física, realizar campañas de convencimiento a la sociedad serenense y a los padres, de la utilidad de aprender una formación básica previa a las disciplinas prácticas.

Formó muchos profesionales para la industria minera y discípulos que fueron sus sucesores en la enseñanza.

También como profesor en La Serena, preparó los programas de estudios con actividades teóricas y prácticas. Escribió y publicó textos de estudio indispensables de física, química, mineralogía y de ensayos de metales.

En La Serena se publicaron sus obras Tratados de Ensayes y Mineralogía, entre los años 1844 y 1845, siendo los primeros tratados de química y mineralogía publicados en el país. Más adelante publicó, como profesor del Instituto Nacional, el texto Elementos de Física Experimental y de Meteorología.

Tan destacables eran sus dotes de educador y vocación de maestro al servicio de los jóvenes que junto a las técnicas pedagógicas utilizadas en la enseñanza, colocó su cualidad personal de gran respeto a sus alumnos atendiendo con paciencia y cariño a los menos aventajados, apoyándolos especialmente en su avance; con lo cual ponía en práctica un principio fundamental en esta época que es la atención a la diversidad y a la equidad académica, velando porque todos sus alumnos lograran al máximo sus aprendizajes. 
Especial mención hace a la juventud, cuando en uno de sus libros señala textualmente: "lo dedico a la estudiosa juventud chilena, a cuyos adelantamientos tengo el más vivo deseo de contribuir". Con lo cual manifiesta su gran alma de maestro, comprometiéndose con nuestra realidad y el desarrollo de los jóvenes.

También como profesor diseñó una verdadera doctrina de vida profesional, que todos los educadores debemos tener presente en nuestra labor: "la principal recompensa que los profesores deberían reclamar, sería un cierto respeto de parte de sus conciudadanos y un contento interior de haber servido e ilustrado a la patria".

Es así como además de un gran científico, Ignacio Domeyko fue un gran humanista que generosamente entregó su saber a los jóvenes y a la patria que lo acogió. La entrega no se concretó sólo a sus conocimientos y su preparación científica, sino también la reforzó con sus libros y todos los recursos que trajo desde Francia, para contribuir a formar a los jóvenes. Incluso le abrió las puertas a varios de ellos para que continuaran su labor perfeccionándose en el extranjero.

En términos actuales, deberíamos decir que Domeyko inició la enseñanza de las ciencias en nuestro país, considerando una formación centrada en el alumno, pertinente, contextualizada, utilizando metodologías activo-participativas, relacionando teoría y práctica, desarrollando en sus alumnos la capacidad indagadora, orientando sus aprendizajes a la autoconstrucción de los conocimientos y atendiendo a la diversidad.

En 1846 Domeyko finalizó su contrato en La Serena, sin embargo sus discípulos continuaron la formación de Ingenieros de Minas, a través del curso de Química y Mineralogía hasta la transformación de éste, el 26 de Agosto de 1887, en la Escuela Práctica de Minería, la que recibió la tradición de Domeyko en la ensenanza caracterizada, en síntesis, por una fuerte formación básica en ciencias y en disciplinas de la ingeniería, mucho trabajo de laboratorio y experiencia práctica, e intensa vocación de los profesores por enseñar a los jóvenes.

Entre otras de sus múltiples cualidades personales, son destacables aquellas que caracterizan a un verdadero creador de conocimiento: la sobriedad, la curiosidad y el rigor científico. Era una autoridad científica en el conocimiento geológico.

Sus artículos sobre análisis químicos de minerales chilenos, aparecen citados ya desde el año 1840, casi recién llegado a La Serena, en prestigiosas publicaciones de Francia, Polonia y en los Anales de la Universidad de Chile. 
En sus publicaciones se evidencia la variedad de las temáticas que abordó, clada su multiplicidad de intereses en el campo de las ciencias, así como: estudios de aguas minerales, tratados de ensayes, mineralogía, fenómenos meteorológicos, ciencias naturales y geología.

Importante aporte significó especialmente el análisis y descripción de los minerales que descubrió: arquevita, las embolitas, la amiolita, sulfatos de plata con cobre, de mercurio con cobre, y de cobre arsenical.

Sus trabajos tuvieron el reconocimiento de otros científicos que lo homenajearon, dando su nombre a hallazgos realizados por Domeyko. Podemos mencionar como el mineralogista Haidinger llamó Domeykit al arseniuro de cobre; Claudio Gay asignó el nombre de Viola Domeykana a una especie de violeta; Bayle y Coquand nombraron como Amonities Domeykanus a fragmentos de Amonita; Alcides I)'Orbigny dẹsignó como Nautilus Domeyku a una especie de fósil; todos éstos, entre otros, encontrados y estudiados por 1)omeyko.

Finalizo esta breve presentación señalando que el Departamento de Ingeniería de Minas de la Universidad de La Serena, es el continuador de la Escuela Práctica de Minería y atesora como patrimonio, la valiosa colección mineralógica de I omeyko integrada por 2400 muestras de minerales, rocas, meteoritos, tanto nacionales como de otros países, entre los cuales se encuentran la Arquerita y la Algodonita.

En la Universidad de La Serena nos sentimos orgullosos de contar con el patrimonio de prestigio, acción y pensamiento de Ignacio Domeyko que nos ha mostrado un camino, no sólo en la mineralogía y las ciencias, sino también en las ideas peclagógicas y de compromiso con la patria, que nos identifican en nuestro quehacer educativo actual. 